\title{
Approximation of theoretical energy-saving potentials for the petrochemical industry using energy balances for 68 key processes
}

\author{
Maarten Neelis ${ }^{\mathrm{a}, *}$, Martin Patel ${ }^{\mathrm{a}}$, Kornelis Blok ${ }^{\mathrm{a}}$, Wim Haije ${ }^{\mathrm{b}}$, Pieter Bach ${ }^{\mathrm{b}}$ \\ ${ }^{a}$ Utrecht University, Copernicus Institute, Unit of Science Technology and Society, Heidelberglaan 2, 3584 CS Utrecht, The Netherlands \\ ${ }^{\mathrm{b}}$ Energy research Centre of the Netherlands, Unit Energy Efficiency in Industry, Westerduinweg 3, 1755 ZG Petten, The Netherlands
}

Received 1 May 2006

\begin{abstract}
We prepared energy and carbon balances for 68 petrochemical processes in the petrochemical industry for Western Europe, the Netherlands and the world. We analysed the process energy use in relation to the heat effects of the chemical reactions and quantified in this way the sum of all energy inputs into the processes that do not end up in the useful products of the process, but are lost as waste heat to the environment. We showed that both process energy use and heat effects of reaction contribute significantly to the overall energy loss of the processes studied and recommend addressing reaction effects explicitly in energy-efficiency studies. We estimated the energy loss in Western Europe in the year 2000 at $1620 \mathrm{PJ}$ of final energy and $1936 \mathrm{PJ}$ of primary energy, resulting in a total of $127 \mathrm{Mt} \mathrm{CO}_{2}$. The losses identified can be regarded as good approximations of the theoretical energy-saving potentials of the processes analysed. The processes with large energy losses in relative (per tonne of product) and absolute (in PJ per year) terms are recommended for more detailed analysis taking into account further thermodynamic, economic, and practical considerations to identify technical and economic energy-saving potentials.
\end{abstract}

(C) 2006 Elsevier Ltd. All rights reserved.

Keywords: Chemical industry; Energy-saving potentials; $\mathrm{CO}_{2}$ emission reduction potentials; Energy loss; Feed loss; Waste heat; Unselectively

\section{Introduction}

In the year 2000, the industrial sector accounted for a final worldwide energy use of $91 \mathrm{EJ}, 32 \%$ of the total energy use. The share of the chemical industry within the industrial sector was $30 \%(27.9,13.5 \mathrm{EJ}$ of which was feedstock) [2]. More energy-efficient technologies in the chemical industry could, therefore, contribute significantly to nationwide and worldwide energy savings and a reduction of $\mathrm{CO}_{2}$ emissions. Several energy-saving directions can be identified for the chemical industry, ranging from short-term implementation of incremental process improvements to innovative, radical new process designs or

This paper is an extended and improved version of a paper presented at the European Congress on Economics and Management of Energy in Industry (ECEMEI), held in Estoril, Portugal on 6-9 June 2004. The conference paper is accepted for publication in a special issue of Applied Energy [1].

*Corresponding author. Tel.: +31030 2537600; fax: + 310302537601 .

E-mail address: m.l.neelis@chem.uu.nl (M. Neelis). new process routes. In order to prioritise research and development (R\&D) efforts directed towards energy savings, it is important to identify the theoretical energysaving potentials for the various processes applied in the chemical industry.

In this paper, we aim to approximate theoretical energysaving potentials for the petrochemical industry by analysing the sum of all energy inputs into the process that do not end up in useful products of the process, but are lost to the environment. These total losses can be divided into three categories:

- In the chemical industry, raw materials are converted to products with a different chemical composition and energy content (see Section 2.2 for further explanation on how the energy content of commodities was calculated). In exothermic reactions, the products have a lower energy content compared with the raw materials and in endothermic reactions the products have a higher energy content compared with the raw materials. From 


\begin{tabular}{|c|c|}
\hline \multicolumn{2}{|c|}{ Abbreviations } \\
\hline $\mathrm{ACN}$ & acrylonitrile \\
\hline BAT & best available technology \\
\hline CHP & combined heat and power \\
\hline DMT & dimethylterephthalate \\
\hline EU & European Union \\
\hline \multicolumn{2}{|c|}{ HDMA hexamethylene diamine } \\
\hline HP & high pressure \\
\hline LCA & life-cycle analysis \\
\hline LHV & lower heating value \\
\hline LP & low pressure \\
\hline LPG & liquefied petroleum gas \\
\hline MDI & diphenyl-4,4-diisocyanate \\
\hline
\end{tabular}

an energy-balance perspective, exothermic processes can export energy and have a negative theoretical energy requirement. Endothermic processes, on the other hand, always require energy. All chemical processes use more process energy than suggested by the theoretical minimum energy requirement calculated based on the energy balance. We define the excess final energy use as the difference between actual process energy use and the theoretical minimum energy requirements based on the energy balance.

- Some of the raw material in a number of processes is not converted to the desired product or products; it is lost. We refer to these losses as losses due to non-selectivity. They can be the result of either the formation of undesired low-value fuel-grade by-products or the overoxidation of the raw material, which results in process heat.

- The third type of loss comprises losses resulting from the production of steam and electricity from primary energy carriers. We refer to these as energy-conversion losses.

The overview given above indicates that process energy use as such is a poor indicator of the total energy loss of a process and cannot serve as a basis to assess theoretical energy-saving potentials, because it does not account for the heat effect of the chemical reactions taking place in the process. In detailed studies on energy-saving potentials of individual processes and in more theoretical studies on potentials for energy savings in chemical processes, the heat effect of reaction is always regarded a key element in understanding the structure of energy use in a process (e.g., [3-7] just to name a few). In contrast to these detailed studies, overview studies focussing on energy in the chemical industry as a whole do not usually address the heat effects of chemical reactions [8-13]. They focus mainly on the process energy use of the various processes. One exception is a study by Lange [14] in which the heat effect of the reaction is considered to be an important element in understanding the cost structure of processes in the chemical industry. That study, however, gives no totals

$\begin{array}{ll}\text { MP } & \text { middle pressure } \\ \text { MTBE } & \text { methyl tert-butyl ether } \\ \text { NL } & \text { Netherlands } \\ \text { PET } & \text { polyethylene terephthalate } \\ \text { PO } & \text { propylene oxide } \\ \text { TBA } & \text { tert-butyl alcohol } \\ \text { TDI } & \text { toluene diisocyanate } \\ \text { WE } & \text { Western Europe }\end{array}$

\section{Subscripts}

$\begin{array}{ll}\text { e } & \text { electricity } \\ \mathrm{f} & \text { final } \\ \mathrm{p} & \text { primary }\end{array}$

for the sum of the processes studied and only discusses a few of the specific processes individually. Tonkovich and Gerber [15] and Lange [16] quantified carbon losses resulting from non-selectivity for a large number of processes, but they do not directly relate these losses to the energy content of raw materials and products.

The present paper extends the existing body of work by presenting a comprehensive overview study that quantifies bottom-up total energy losses in the petrochemical industry. The losses are identified in relative terms (per tonne of product) for the individual processes and in absolute terms (PJ per year) for the totals of the processes studied in the Netherlands, Western Europe (EU-15 + Norway and Switzerland), and the world for the year 2000. Total $\mathrm{CO}_{2}$ emissions resulting from the energy loss are also quantified. Section 2 presents our research approach and input data and Section 3 discusses the results of the analysis.

Our analysis comprises an energy analysis that quantifies the difference in energy content between all process inputs and the products of the process at standard conditions ( $298.15 \mathrm{~K}$ and 1 bar). The individual processes are studied as black boxes, i.e., the flows between the various unit operations (reactors, separation equipment, etc.) and the actual temperature and pressures of these flows are not considered. We convert the final process energy use back to primary fuels. At the level considered in this study, an exergy analysis based on the second law of thermodynamics would yield comparable overall results, since the difference between chemical exergy and energy content for fuels and for most of the commodities crossing the system boundaries used in our analysis differ by less than $10 \%$ [17]. As a result, the total energy loss as identified in this study is close to the total exergy loss and can therefore be regarded as a good approximation of the theoretical energy-saving potential of the process analysed. The division over the three loss categories identified would, however, be different in the case of an exergy analysis, which becomes clear from the following example. When steam is produced in a boiler, the energy efficiency is very 
high (we assume $90 \%$ ), but the exergy efficiency is much lower, depending on the temperature and pressure of the steam produced. The exergy conversion losses in the production of steam are therefore much larger than the energy-conversion losses. On the other hand, the process exergy use of a process using steam is much lower than the process energy use, because of the low exergy content of steam compared with the energy content.

As we talk about theoretical potentials, we exclude any considerations of (current) technical or economic feasibility, which are explicitly taken into account when determining technical and economic potentials. This means that our results are more important for the longer term. They provide an indication of processes where-in principle-large savings can be achieved. The lists of processes presented can in that sense be regarded as priority lists for R\&D programmes. To identify technical and economic energy-saving potentials based on our results, more detailed analyses are required taking into account further thermodynamic (including aspects related to the second law of thermodynamics such as the necessity for driving forces required for reactions and heat transfer) as well as economic and practical considerations related to energy-saving options. In Section 4, we briefly discuss this further and give some general energy-saving directions based on our results. The discussion (Section 5) identifies the main uncertainties associated with the approach we used and compares our results with other available sources. Finally, conclusions are given in Section 6.

\section{Research approach, input data, and basic assumptions}

\subsection{Model overview}

For our analysis, we used a spreadsheet model containing the production processes of 51 (listed in Appendix A) of the most important petrochemicals with respect to production volume. The selection of products was based on available data. Of the petrochemicals listed in the US production of top 50 chemicals [10], we did not include vinyl acetate (no. 37), methyl chloride (no. 48) and methyl methacrylate (no. 50). We also included ammonia (hydrocarbon feedstock) and chlorine (very important intermediate for the petrochemical industry). Since some of the products can be produced by more than one process route, the total number of processes included was 68. For a number of processes, there was more than one dataset available and approximately 300 datasets are therefore included in the spreadsheet model. We used the dataset most likely to represent the average technology in use in Western Europe in 2000. When there was only one process dataset available, we used that dataset in the analysis without adjusting for process improvements that might have taken place over time.

The variables included for each of the datasets are shown in Fig. 1. We calculated various energy and $\mathrm{CO}_{2}$ emission indicators based on these variables. Table 1 presents the definition of the indicators for which results are discussed in Section 3. Throughout the paper, we refer to the variables and indicators shown in Fig. 1 and Table 1 without explicit reference.

In most of the included processes, raw materials are converted into products having a different chemical composition. In the processes that stand at the beginning of the chain of chemical conversions, the raw material is often a commodity, which is included in energy statistics. Two examples are the use of naphtha in olefin production and natural gas in ammonia production ${ }^{1}$. In the majority of processes included, however, the raw material is a basic or intermediate chemical commodity with a uniform and well-defined chemical composition, which is further converted to another chemical commodity (e.g., the conversion of ethylene to ethylene oxide). The heat of the stoichiometric reaction $\left(\Delta H_{\text {reaction }}\right)$ from raw material to the desired product or products is included (variable 22) in the model. Some processes produce not only the desired products, but also small amounts of organic or inorganic by-products. In our model, we included only sellable chemical-grade commodities as by-products of a process and not the production of undesired fuel-grade byproducts, which we considered part of the losses due to non-selectivity. An exception is made for the steam cracking process; for this process, we included all products, including the fuel by-products (see Section 3 and Appendix A for details). We also included the mass, molar quantity, and energy content for the raw materials, products, and byproducts of the processes. Normally, only the flows in mass units are given in the datasets from literature that are the basis of our model. The assumptions made in estimating the remaining variables from these mass flows are explained in Section 2.2. Also studied was the process energy use, divided into direct fuel use, steam use, and electricity use. We did, however, not separately identify various types of end uses (e.g., compression, pumping, heating etc.) of the process energy use. For electricity and steam use, we included both final energy use and primary fuel equivalents. Final energy use is expressed throughout this paper with subscript $f$ or e (for electricity), primary energy equivalents with subscript $\mathrm{p}$. The assumptions made for energy-conversion efficiencies and $\mathrm{CO}_{2}$ emissions factors are explained in Section 2.3. We did not include additional non-energy inputs into the processes that were not part of the conversions taking place, such as cooling water, solvents and catalysts.

Our model also contains production figures for chemical commodities for three geographical regions in the year 2000: the Netherlands (NL), Western Europe (WE), and the world. The share of each process route in the total production is also incorporated for those chemicals for

\footnotetext{
${ }^{1}$ In international energy statistics (e.g., [18]), the use of energy commodities as raw material in the chemical industry is included as a memo item under the final consumption of the chemical industry and is referred to as feedstock use in the chemical industry. See Section 5 for a comparison between our data and the data from international energy statistics.
} 


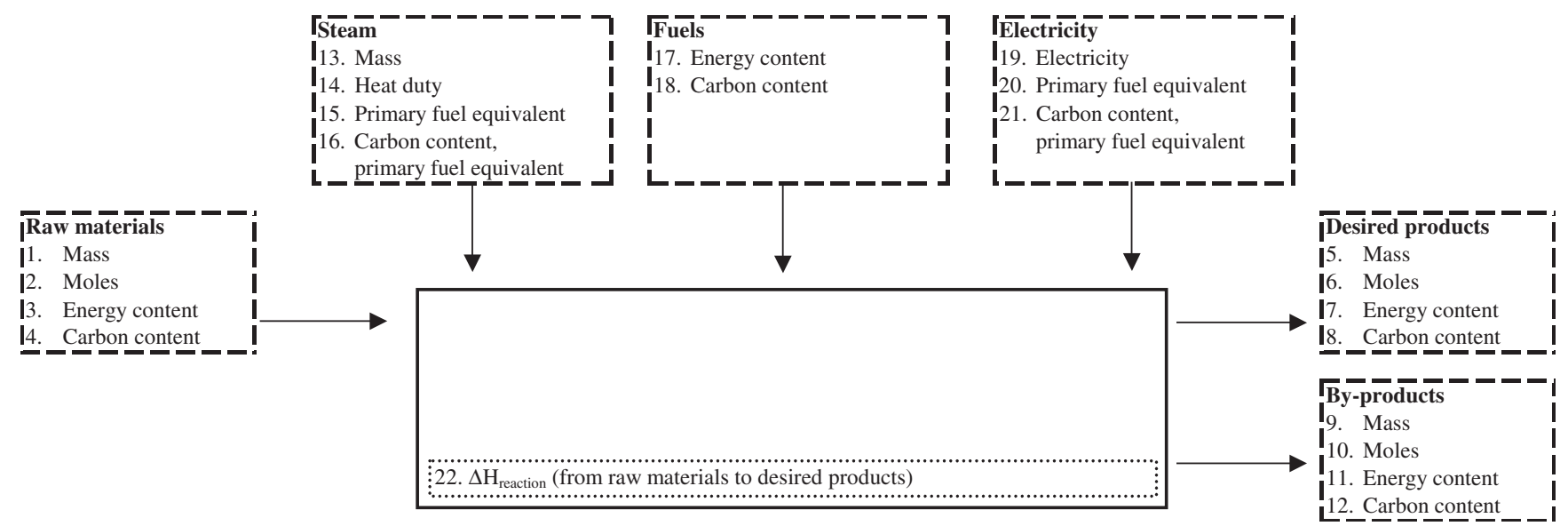

Fig. 1. Overview of the variables included in the datasets.

Table 1

Definition of indicators

\begin{tabular}{lll}
\hline No. & Indicator name (unit) & $\begin{array}{l}\text { Formula (numbers refer to the } \\
\text { variables in Fig. 1) }\end{array}$ \\
\hline 1 & $\begin{array}{l}\text { Theoretical final energy use } \\
\left(\mathrm{J}_{\mathrm{f}}\right)\end{array}$ & +22 \\
& $\begin{array}{l}\text { Theoretical heat effect of } \\
\text { reaction }\left(\mathrm{J}_{\mathrm{f}}\right)\end{array}$ & -22 \\
3 & Total final energy use $\left(\mathrm{J}_{\mathrm{f}}\right)$ & $14+17+19$ \\
4 & Total primary energy use $\left(\mathrm{J}_{\mathrm{p}}\right)$ & $15+17+20$ \\
5 & Heat effect of reaction $\left(\mathrm{J}_{\mathrm{f}}\right)$ & $3-7-11$ \\
6 & Energy-conversion losses $\left(\mathrm{J}_{\mathrm{p}}\right)$ & $15+20-14-19$ \\
7 & Total final energy loss $\left(\mathrm{J}_{\mathrm{f}}\right)$ & $14+17+19+3-7-11$ \\
8 & Total primary energy loss $\left(\mathrm{J}_{\mathrm{f}}\right)$ & $15+17+20+3-7-11$ \\
9 & Excess final energy use $\left(\mathrm{J}_{\mathrm{f}}\right)$ & $14+17+19-22$ \\
10 & Losses due to non-selectivity & $3-7-11+22$ \\
& $\left(\mathrm{~J}_{\mathrm{f}}\right)$ & \\
11 & Carbon losses, energy use, & $16+18+21$ \\
& primary $(t$ CO \\
\end{tabular}

which different process routes are included in the analysis, again for the three geographical regions included. The sources of the production volumes and process shares are discussed in Section 2.4.

\subsection{Properties of raw materials, products, and by-products}

For chemical commodities with a well-defined chemical composition, we converted the quantities in mass units to moles and carbon content using the molecular composition of the commodity. The energy content of a commodity containing carbon, hydrogen, and/or sulphur (molecular composition $\left.\mathrm{C}_{x} \mathrm{H}_{y} \mathrm{~S}_{z}\right)$ was calculated based on the heat of formation $\left(\Delta H_{\text {formation }}\right)$ using the following formula:

Energy content $=x \times H_{\text {formation, } \mathrm{CO}_{2}(\mathrm{~g})}+(y / 2) \times \Delta H_{\text {formation, } \mathrm{H}_{2} \mathrm{O}(\mathrm{g})}$

$$
+z \times \Delta H_{\text {formation, } \mathrm{SO}_{2}(\mathrm{~g})} H_{\text {formation, commodity }} \text {. }
$$

This formula calculates the energy content, using $\mathrm{CO}_{2}, \mathrm{H}_{2} \mathrm{O}$ and $\mathrm{SO}_{2}$ as the reference substances for the elements carbon, hydrogen and sulphur. The pure elements are implicitly taken as the reference substance for the other elements (if present in the commodity) ${ }^{2}$. For fuel commodities containing just hydrogen, carbon, sulphur, and nitrogen (i.e., the majority of the commodities involved in our analysis), the energy content as calculated with Formula 1 is normally referred to as the calorific value (lower heating value, LHV) in literature. The heat of formation of the commodities was taken from Aspen Plus flowsheeting software [19]. For the commodities not present in that dataset, the heat of formation was calculated based on Brandrup and Immergut [20] or by using estimation methods given in Szargut et al. [17]. For the energy commodities used as raw material in the chemical industry (e.g., natural gas and naphtha), we employed the energy content (calorific value) and $\mathrm{CO}_{2}$ emission factors reported by IPCC/IEA/OECD/ UNEP [21].

\subsection{Properties for electricity, fuels and steam}

Using IEA publications [2,18], we derived an overall $\mathrm{CO}_{2}$ emission factor of $62 \mathrm{~kg} \mathrm{CO}_{2} / \mathrm{GJ}$ for the fuel mix used for final consumption in the chemical industry in Western Europe. This emission factor was then applied to calculate the associated $\mathrm{CO}_{2}$ emissions of the fuel use reported in the datasets (variable 18). For the fuels used in the steam cracking and steam reforming processes, we use processspecific emission factors, which are explained in the notes

\footnotetext{
${ }^{2}$ This choice was made for practical reasons: all losses of hydrogen, carbon and sulphur were implicitly assumed to leave the process as $\mathrm{CO}_{2}$, $\mathrm{H}_{2} \mathrm{O}$, and $\mathrm{SO}_{2}$, respectively, with an energy content of 0 . Another option would be to use the heat of formation of commodities directly as energy content (taking the pure elements as reference for all elements present in the commodity). With such a reference system, however, the losses of carbon, hydrogen and sulphur in the form of $\mathrm{CO}_{2}, \mathrm{H}_{2} \mathrm{O}$ and $\mathrm{SO}_{2}$ should be quantified to avoid mistakes, because the energy content of these substances is then not equal to 0 .
} 
to Appendix A. The datasets used in some cases distinguish between low-pressure (LP), middle-pressure (MP) and high-pressure (HP) steam. We assumed heat duties of 2.4, 2.6, and $2.8 \mathrm{GJ}_{\mathrm{f}} /$ tonne for $\mathrm{LP}, \mathrm{MP}$ and $\mathrm{HP}$ steam, respectively ${ }^{3}$. In cases where the type of steam was not specified in the dataset, we used the properties of MP steam. We assume this heat duty (final energy) to be produced from fossil fuels with a boiler having an energy efficiency of $90 \%$ to calculate primary fuel equivalents. For the fuels used in steam generation, we used the same emission factors as we used for direct fuel use $\left(62 \mathrm{~kg} \mathrm{CO}_{2} /\right.$ GJ). For electricity, we used a $41 \%$ efficiency for the conversion from final to primary fuel equivalents and a $210 \mathrm{~kg} \mathrm{CO} / \mathrm{GJ}_{\mathrm{e}}$ emission factor, based on data in Graus and Voogt [24] for fossil electricity generation in Germany, France, the UK+Ireland, and the Nordic European countries.

\subsection{Sources for production data and for shares of production processes}

The majority of production figures of the chemicals for the year 2000 (given in Appendix A) were obtained from the chemical profile pages published in Chemical Market Reporter [25], the product profile pages in European Chemical News [26] and the product focus pages in Chemical Week [27]. These sources were complemented with data from grey literature and textbooks containing production figures (e.g., Weissermel and Arpe [28]). Publicly available company data were also used in some cases. If there was just data for years close to 2000, we used linear inter- and extrapolations to obtain production data for 2000 or applied the growth rates mentioned in the literature. In cases where only capacity data were available, we used capacity-utilisation rates mentioned in the literature source or a default capacity utilisation rate of $86 \%$, a value for the Dutch chemical industry in the period 1999-2003 [29]. For chemicals produced via more than one process route, the shares of the various process routes were obtained in most cases from Weissermel and Arpe [28] and complemented with other sources like the three journals given above.

\section{Results}

The results in absolute terms shown in this section refer to calculations for Western Europe in the year 2000. The corresponding results for the Netherlands and the world can be deducted from Appendix A and Figs. 8 and 9 in Section 3.3. Background data on the 68 individual processes included in the model are summarised in

\footnotetext{
${ }^{3} \mathrm{We}$ assumed pressure and temperature of $4 \mathrm{bar} / 175^{\circ} \mathrm{C}$ for LP steam, $10 \mathrm{bar} / 280^{\circ} \mathrm{C}$ for MP steam and $40 \mathrm{bar} / 400^{\circ} \mathrm{C}$ for $\mathrm{HP}$ steam respectively, based on Patel [22]. The heat duty was considered equal to the enthalpy difference between steam having these temperature and pressure levels and liquid water at $25^{\circ} \mathrm{C}$, corrected for return condensate having an enthalpy of $0.4 \mathrm{GJ} /$ tonne compared with liquid water at $25^{\circ} \mathrm{C}$ [23]
}

Appendix A and documented in more detail in Neelis et al. $[30]^{4}$.

\subsection{Excess final energy use}

From an energy-balance perspective, exothermic processes can export energy and have a negative theoretical energy requirement. Endothermic processes, on the other hand, always require energy. We define the theoretical final energy use (from an energy-balance perspective) as the $\Delta H_{\text {reaction }}$ from raw materials to desired products (indicator 1, variable 22). Fig. 2 shows the actual final energy use (indicator 3) as a function of this theoretical final energy use. As can be seen in Fig. 2, most processes included in the model are exothermic: i.e., the products of the process have an energy content that is lower than the energy content of the raw material entering the process. Endothermic processes are the steam cracking process ${ }^{5}$, the production of chlorine, and the dehydrogenations of ethylbenzene to styrene and isopropanol to acetone. In these processes the products have a higher energy content than the raw material. Fig. 2 shows that some of the processes involving exothermic reactions recover energy available from the exothermic reaction to the extent that they become net exporters of energy in the form of steam. The majority of the exothermic processes, however, are net consumers of process energy. We defined the excess final energy use of a process (indicator 9) as the difference between the actual and theoretical final energy use (i.e., the distance between the data points and the line $y=x$ ) and listed the 10 processes with the largest excess final energy use.

We converted the indicators shown in GJ per tonne of product to total PJ per year, taking into account production volumes and shares of the various process routes. A graph of the excess final energy use for the sum of all processes is shown in Fig. 3 as are the 10 processes with the largest excess final energy use. The total excess final energy use for the sum of the processes included in the analysis was estimated to be $1482 \mathrm{PJ}_{\mathrm{f}}$ in 2000 . We could not calculate the heat of the stoichiometric reaction and the heat effect of reaction with sufficient accuracy for a limited number of processes (see notes in Appendix A). For those

\footnotetext{
${ }^{4}$ The results in this paper differ slightly from those in Neelis et al. [30]. In the present paper we use a different efficiency and emission factor for electricity production, made additional corrections for by-products of $\mathrm{PO}$, MDI, and TDI production (see notes to Appendix A), and corrected the worldwide production volume for PET.

${ }^{5}$ The steam cracking process to produce olefins and aromatics is included in such a way that the internal use of part of the fuel products is visible. No ideal desired stoichiometric reaction is defined, because of the multiple products produced. Instead, the stoichiometric heat of reaction is set equal to the heat effect of reaction, which is calculated as the difference between the total cracker output and the cracker input. Part of the cracker output (i.e., the fuel by-products) is used to fuel the process. This amount is included as final fuel use. The resultant figures are expressed per tonne of total products produced.
} 


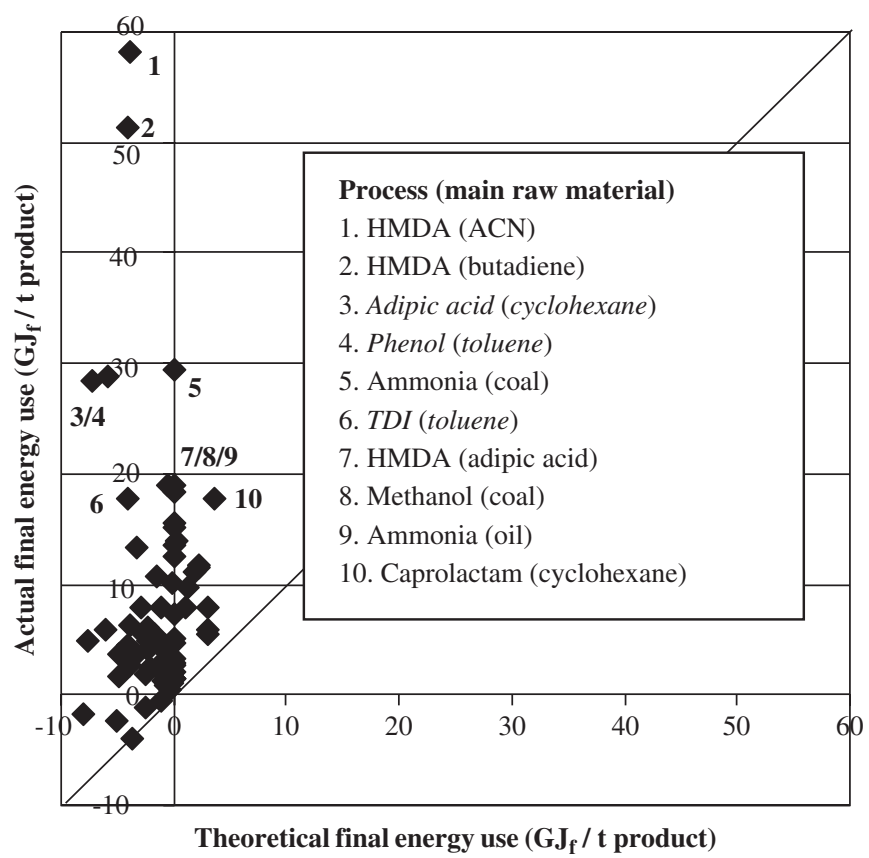

Fig. 2. Theoretical final energy use $\left(\Delta H_{\text {reaction}}\right.$, indicator 1) versus actual final energy use (indicator 3). Note: the processes printed in italics are uncertain estimates based on single sources published before 1990 (see Section 5).

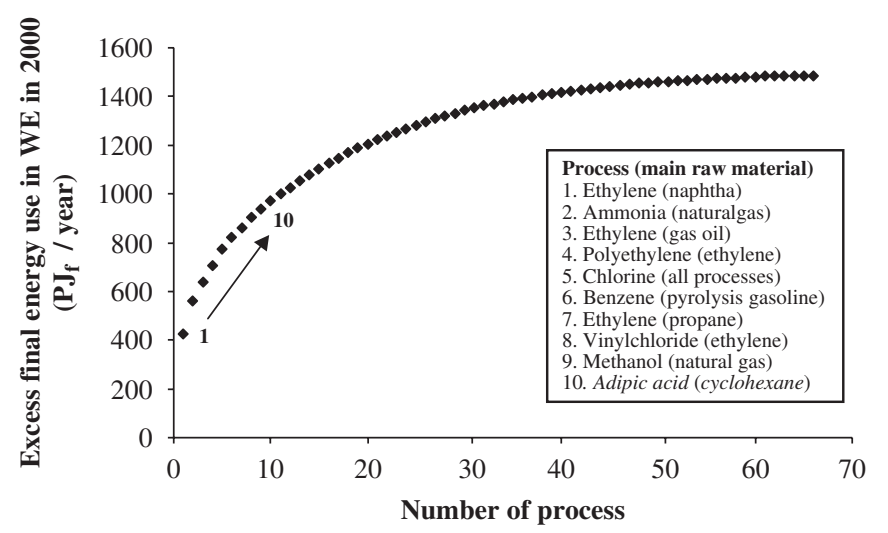

Fig. 3. Excess final energy use (indicator 9) in WE in 2000 for the processes included in the model, ranked in the order of decreasing total excess final energy use. Note: the process printed in italics is uncertain estimate based on single sources published before 1990 (see Section 5).

processes, we set the excess final energy use in Fig. 3 equal to the total final energy use.

\subsection{Losses due to non-selectivity}

In many processes, part of the raw material is not converted to the desired products - it is lost. We refer to this type of loss as losses due to non-selectivity and quantify them by comparing the actual difference in energy content between the raw materials and products of the process (indicator 5) with the theoretical difference in energy content between raw materials and desired products. The

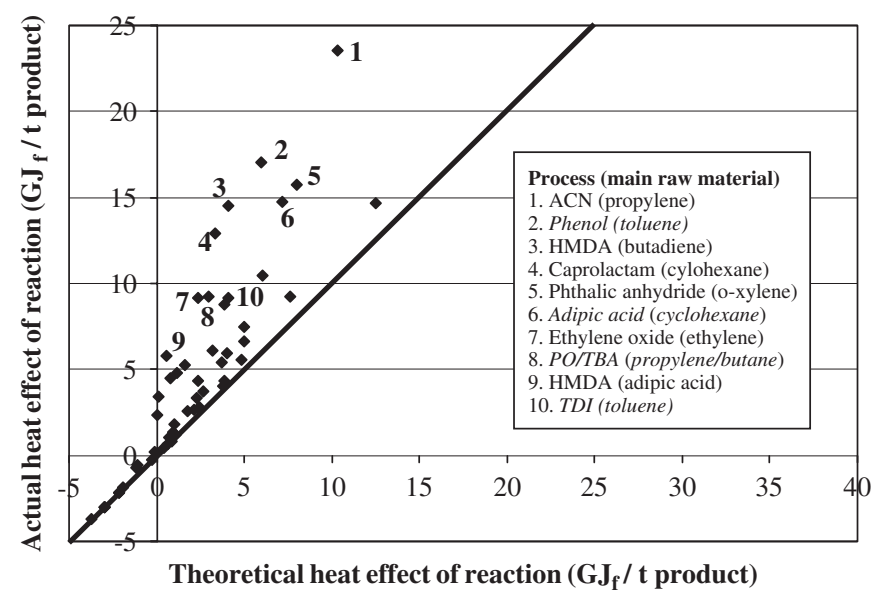

Fig. 4. Theoretical heat effect of reaction $\left(-\Delta H_{\text {reaction }}\right.$, indicator 2$)$ versus actual heat effect of reaction (indicator 5). Note: the processes printed in italics are uncertain estimates based on single sources published before 1990 (see Section 5).

latter is equal to the negative value of the $\Delta H_{\text {reaction }}$ from raw materials to desired products (indicator 2$)^{6}$. We show this comparison in Fig. 4. Processes that have a $100 \%$ conversion from raw materials to desired products according to the stoichiometric reaction are located on the $y=x$ line shown in Fig. 4. In practice, however, not all of the raw material is converted to the desired products: it is lost due to non-selectivity. This loss (indicator 10) is equal to the vertical distance between the data points and the $y=x$ line.

The losses due to non-selectivity can be the result of either the formation of undesired low-value fuel-grade byproducts $^{7}$ or the over-oxidation of the hydrocarbon raw materials, leading to process heat and direct $\mathrm{CO}_{2}$ emissions. The energy in the second case becomes directly available as process heat within the reactor, whereas the energy in the first case is embodied in low-value byproducts that might be burned with energy recovery. It is not always clear whether the second type of energy recovery is netted off in the process datasets as found in literature. Part of the losses due to non-selectivity, therefore, might have been double-counted in our analysis, first as losses due to non-selectivity and again as final energy use (for a discussion, see Section 5). It should be noted that the effect of raw material losses on the heat effects of reaction is substantial. If 0.01 tonne of a hydrocarbon raw material is lost per tonne of product, the heat effect of reaction increases by $0.1-0.5 \mathrm{GJ}_{\mathrm{f}} /$ tonne in the form of either heat or

\footnotetext{
${ }^{6}$ In our approach, the heat effect of reaction is the difference in energy content between the raw materials and the products of a process. Thus, exothermic reactions in our model have a positive heat effect of reaction and endothermic reactions a negative heat effect of reaction (Table 1). This is exactly opposite to the convention used for the $\Delta \underline{H}_{\text {reaction }}$ (variable 22).

${ }^{7}$ Although some products might be valuable, their concentrations might be too low to justify a complicated and/or expensive product separation process. The losses due to non-selectivity also include losses via light and heavy purge (bleed) streams in recycle loops.
} 
low-value by-products (considering that the energy content of the hydrocarbons used as raw materials ranges between 10 and $50 \mathrm{GJ} /$ tonne). This constitutes a significant fraction of the heat of reaction of most processes, as shown in Fig. 4. The 10 processes with the largest losses due to nonselectivity are also listed in Fig. 4. The list shows that oxidation reactions, in particular, are often difficult to control in a selective way. In ethylene oxide production, for example, 18 mass $\%$ of the ethylene is burned rather than converted to ethylene oxide. This results in a heat effect of reaction of $9.1 \mathrm{GJ}_{\mathrm{f}} /$ tonne ethylene oxide rather than the $2.4 \mathrm{GJ}_{\mathrm{f}} /$ tonne in the case of a stoichiometric conversion from ethylene to ethylene oxide.

As with the excess final energy use, we converted the losses due to non-selectivity per tonne of product to total losses per year, taking into account the production volumes of the chemical commodities and the shares of the various process routes. A graph of the losses due to non-selectivity for the sum of the processes and a list of the 10 processes with largest losses in 2000 are presented in Fig. 5. Total losses due to non-selectivity of the processes analysed amounted to $138 \mathrm{PJ}_{\mathrm{f}}$ in 2000 . Losses due to non-selectivity are small compared with the excess final energy use of the processes (138 and $1482 \mathrm{PJ}_{\mathrm{f}}$, respectively; compare Fig. 3 with Fig. 5). The economic importance of these losses, however, is more significant because raw material costs are generally much higher than energy costs. Furthermore, it is important to realise that raw material losses also result in avoidable energy use in the more upstream processes to produce this raw material, an effect that we did not quantify in this study.

\subsection{Total energy losses and $\mathrm{CO}_{2}$ emissions}

The total final energy loss of the processes (indicator 7) equals the sum of the heat effect of reaction (indicator 5)

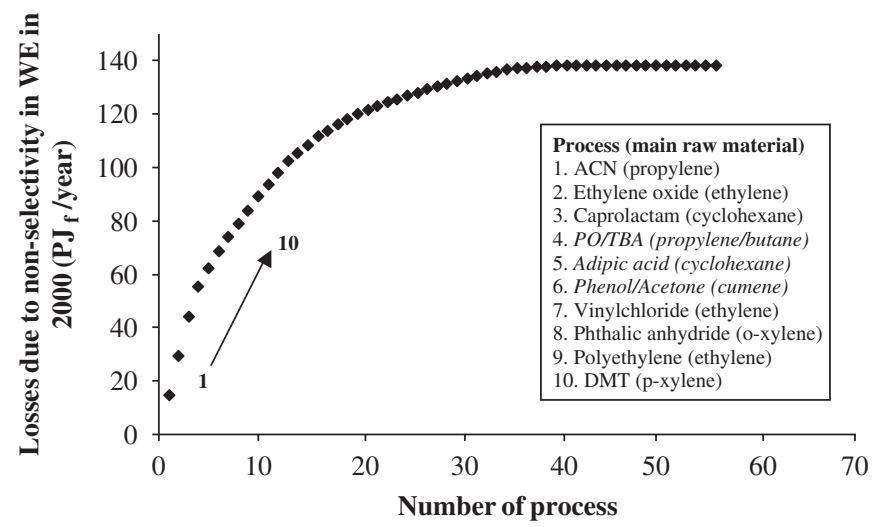

Fig. 5. Losses due to non-selectivity (indicator 10) in WE in 2000 for the processes included in the model, ranked in the order of decreasing losses due to non-selectivity. Note: we excluded the processes for which the heat of the stoichiometric reaction and the reaction effects are not included (Appendix A). The processes printed in italics are uncertain estimates based on single sources published before 1990 (see Section 5). and the total final energy use (indicator 3). By definition, the total final energy loss is also equal to the sum of losses due to non-selectivity (indicator 10) and excess final energy use (indicator 9). The total primary energy loss (indicator 8 ) equals the sum of the final energy loss and the energyconversion losses (indicator 6). The energy-conversion losses are equal to the difference between final and primary energy use (indicator 4-indicator 3).

The contribution of the losses due to non-selectivity, excess final energy use and energy-conversion losses to the total primary energy loss for all processes having a primary energy losses exceeding $15 \mathrm{GJ}_{\mathrm{f}} /$ tonne of product are given in Fig. 6. The processes with large losses due to non-selectivity, a large excess final energy use, and large energy-conversion losses can be readily identified by the three bar sections. We converted the indicators shown in GJ per tonne of product to total PJ per year, taking into account production volumes and shares of the various process routes. The processes with total primary energy losses exceeding $20 \mathrm{PJ}_{\mathrm{p}}$ in 2000 are presented in Fig. 7.

Figs. 8 and 9 show, respectively, the total primary energy loss and the total $\mathrm{CO}_{2}$ emissions in such a way that the energy and $\mathrm{CO}_{2}$ emission profiles of the petrochemical industry become visible. Petrochemical feedstocks (naphtha, gas oil, LPG, ethane) are first converted into basic chemical (olefins and aromatics) in the endothermic steam cracking process ${ }^{8}$. The overall heat effect of reaction of the steam cracking process was estimated to be $-129 \mathrm{PJ}$ (endothermic) in 2000. The endothermic reaction was sustained by burning $689 \mathrm{PJ}_{\mathrm{f}}$ of fuels, leading to a total of $33 \mathrm{Mt} \mathrm{CO}_{2}$ emissions. The total final energy loss in the steam cracking process was therefore $560 \mathrm{PJ}_{\mathrm{f}}(689-129)$. The conversion of sodium chloride to chlorine (another important basic chemical) is also endothermic with a heat effect of reaction of $-62 \mathrm{PJ}_{\mathrm{f}}$ in 2000 . This reaction was sustained by supplying $131 \mathrm{PJ}_{\mathrm{f}}$ of final energy per year, resulting, under the assumptions given in Section 2.3, in a total of $25 \mathrm{Mt} \mathrm{CO}_{2}$ emissions. The total final energy loss therefore equalled $69 \mathrm{PJ}_{\mathrm{f}}$ (131-62). Since the energy input into chlorine production is electricity, the total primary energy loss was much higher $\left(236 \mathrm{PJ}_{\mathrm{p}}\right.$, Fig. 7). Final energy use in the production of a third important basic chemical (ammonia) was estimated to be $152 \mathrm{PJ}_{\mathrm{f}}$ in 2000 (excluding feedstock use, which we defined as the LHV of the ammonia product), resulting in a total of $17 \mathrm{Mt} \mathrm{CO}_{2}$ emissions.

In subsequent chemical conversion steps, heteroatoms are added to the double bonds in the olefins and aromatics produced via steam cracking in conversions that are mainly exothermic. The heat effect of reaction for the sum of these more downstream processes was estimated at $342 \mathrm{PJ}_{\mathrm{f}}$ (exothermic) in 2000. The theoretical heat effect of reaction for the sum of those processes only equalled

\footnotetext{
${ }^{8}$ Some of the aromatics and a small amount of propylene are recovered in refineries and not via steam cracking.
} 


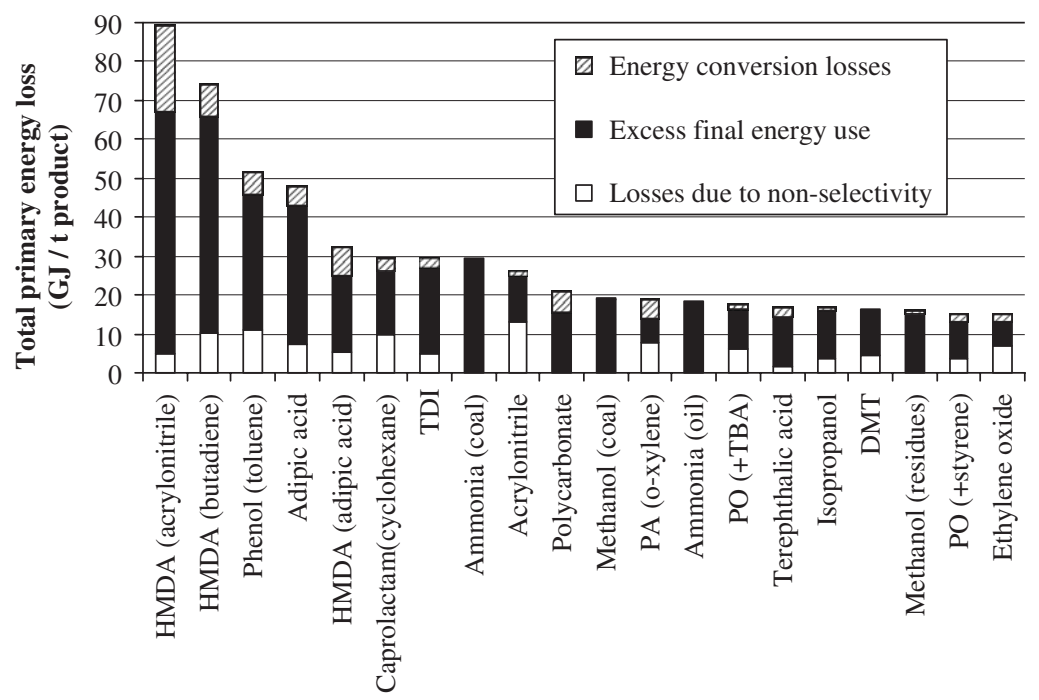

Fig. 6. Processes with total primary energy losses (indicator 8) exceeding $15 \mathrm{GJ}_{\mathrm{p}} /$ tonne product. Note: we considered the final energy use to equal the total final energy use and the losses due to non-selectivity to equal 0 for those processes for which the heat of the stoichiometric reaction and the reaction effects were not included (Appendix A).

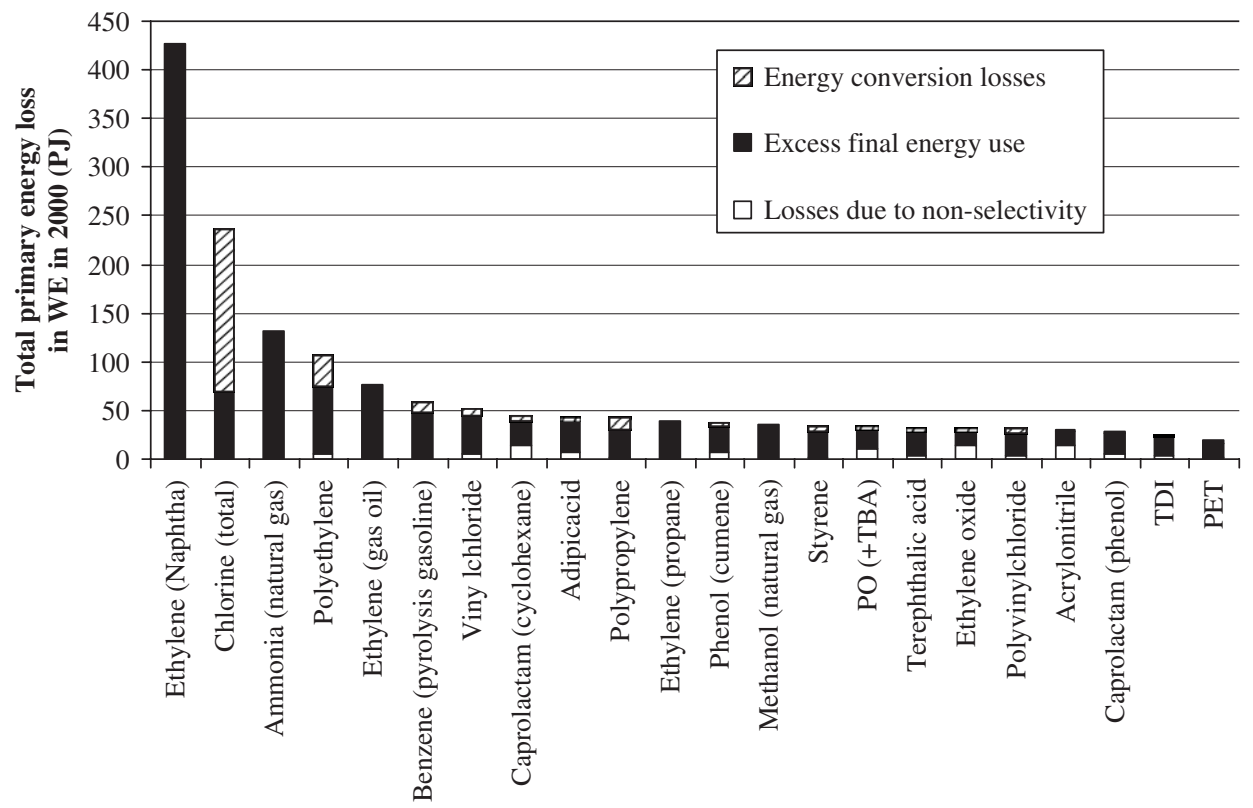

Fig. 7. Processes with total primary energy losses (indicator 8) exceeding $20 \mathrm{PJ}_{\mathrm{p}}$ in Western Europe in 2000. Note: we considered the final energy use equal to the total final energy use and the losses due to non-selectivity equal to 0 for those processes for which the heat of the stoichiometric reaction and the reaction effects were not included (Appendix A).

$204 \mathrm{PJ}_{\mathrm{f}}$. Therefore, more than $40 \%$ of the heat effect of reaction resulted from losses due to non-selectivity $\left(138 \mathrm{PJ}_{\mathrm{f}}\right.$ per year; i.e., 342-204, Fig. 5). Carbon losses resulting from these losses due to non-selectivity were estimated at $9 \mathrm{Mt} \mathrm{CO}_{2}$ in 2000 (excluding emissions from ammonia and methanol production). The remaining processes had a final energy use of $497 \mathrm{PJ}_{\mathrm{f}}$ per year, resulting in $35 \mathrm{Mt} \mathrm{CO}_{2}$ emissions. According to the defined stoichiometric reactions, the processes could produce $204 \mathrm{PJ}_{\mathrm{f}}$ of energy if they ran $100 \%$ according to the defined stoichiometric reactions and without energy losses; in practice they consumed $497 \mathrm{PJ}_{\mathrm{f}}$. The excess final energy use in those processes, therefore, was $701 \mathrm{PJ}_{\mathrm{f}}(497+204)$ in 2000 .

The total final energy loss for the sum of the processes included equalled $1620 \mathrm{PJ}_{\mathrm{f}}$. Since the energy-conversion 


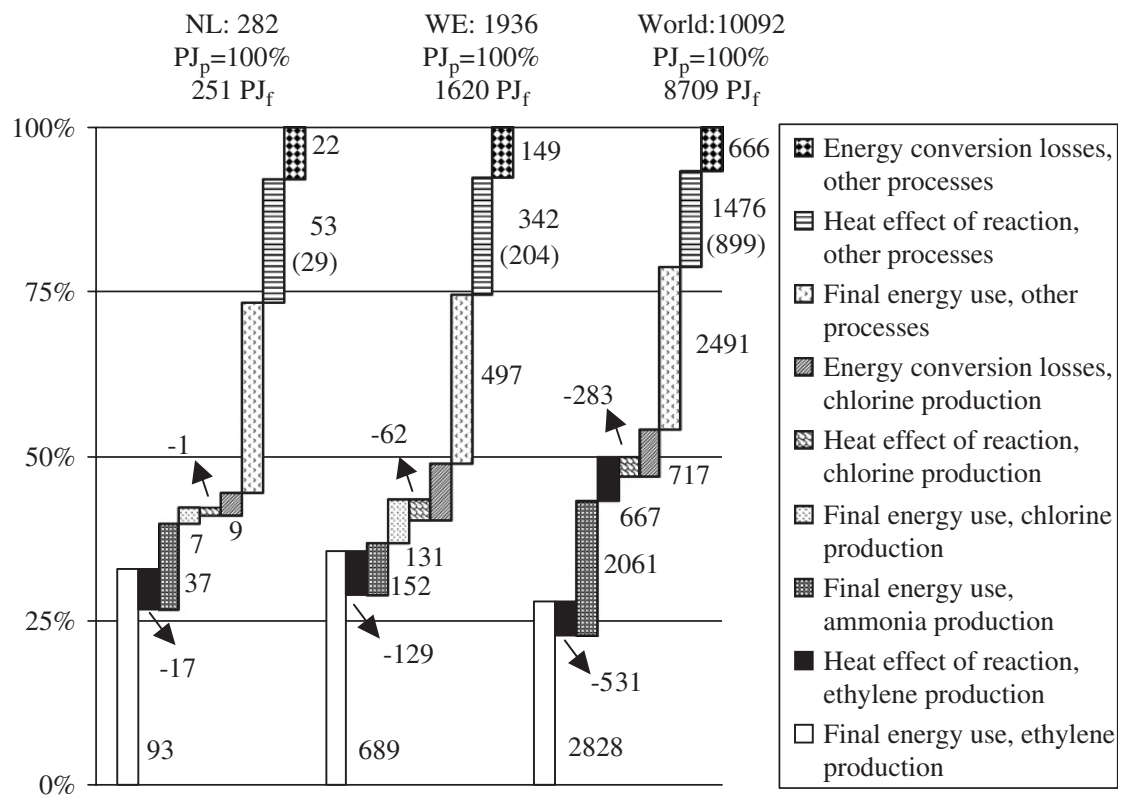

Fig. 8. Overview of the total final and primary energy losses (indicators 7 and 8). Note: ethylene, ammonia and chlorine production are given separately to show their major contribution to the totals. Figures in parentheses are the theoretical heat effects of reaction.

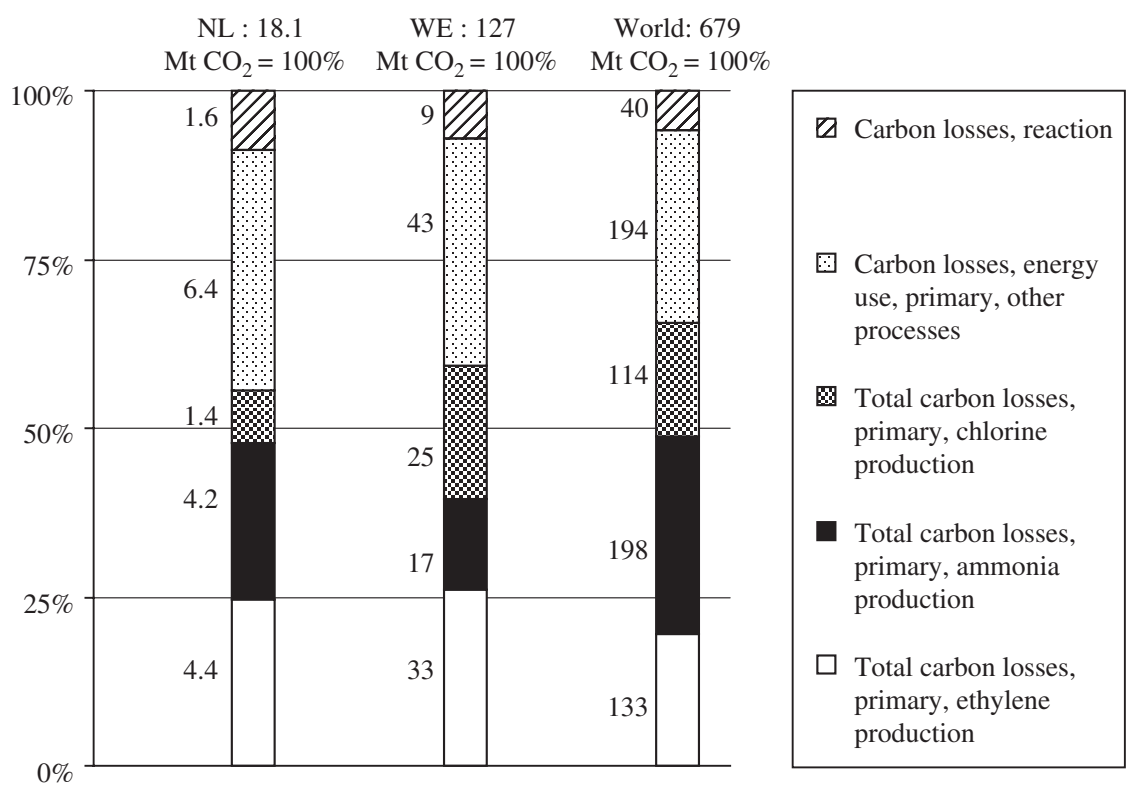

Fig. 9. Overview of total primary carbon losses (indicator 13). Note: ethylene, ammonia and chlorine production are given separately to show their major contribution to the totals.

losses (using the assumptions given in Section 2.3) were estimated to be $316 \mathrm{PJ}_{\mathrm{p}}$, the total primary energy loss equalled $1936 \mathrm{PJ}_{\mathrm{p}}$. The results clearly show that the heat effect and carbon losses of reaction contribute significantly to the overall energy loss and $\mathrm{CO}_{2}$ emissions of the chemical industry. These effects, however, are not directly visible in energy statistics and are often not explicitly addressed or quantified in life cycle analyses and energyefficiency studies for the chemical industry. They should, however, be considered in order to get a proper overview of the energy use and energy saving and $\mathrm{CO}_{2}$ reduction possibilities in the chemical sector. 


\section{General directions for energy savings based on our findings}

Our analysis was based on the first law of thermodynamics and quantified the sum of all energy inputs into the process that do not end up in the useful products of the process, but are lost as waste heat to the environment. As explained in Section 1, the total primary energy loss can be regarded as a good approximation of the theoretical energy-saving potential of the processes involved. To identify technical and economic energy-saving potentials based on our results, it is necessary to conduct more detailed analyses at the level of individual unit operations (e.g., reactors, separation equipment, compressors, etc.) using both first and second law aspects as well as practical and economic considerations related to energy-saving options. The processes with large losses identified in this study (Figs. 2-7) are recommended for such detailed analyses. In this section we will briefly discuss some general directions for energy savings based on our blackbox analysis without having the intention of giving a complete overview.

Our analysis was based on average technology in place in Western Europe in 2000. These processes are less energy efficient than processes using best available techniques (BAT). Based on BAT data for ammonia, methanol and ethylene production (steam cracking), we estimate that for these processes, the energy-saving potential related to the implementation of BAT processes ranges between $10 \%$ and $50 \%$ of the current final energy use [30]. This (rather broad) range indicates that the potential related to the implementation of BAT processes is substantial. Because of the significant uncertainties in both the BAT data and our average process data (see Section 5) and the unavailability of further data on BAT processes, it is, however, difficult to draw more robust conclusions about the total potential related to the implementation of BAT processes.

Based on the distinction between the three types of losses, we distinguish between improvements with the aim to lower the losses due to non-selectivity of processes, those with the aim to lower the excess final energy use of processes and those with the aim to lower the energy-conversion losses of the processes. Energyconversion losses can be lowered by more efficient steam and electricity production (e.g., combined heat and power production) or by switching from electricity to fuel use where possible (e.g., avoid the use of electricity for heating purposes). This is not further discussed in the present paper.

With the exception of polyethylene, all processes listed in the top 10 of processes with the largest losses due to nonselectivity (Fig. 5) involve oxidation reactions. These reactions are often difficult to control in a selective way. Over-oxidation in these processes results in the formation of by-products such as hydrogen cyanide in the production of acrylonitrile and $\mathrm{CO}_{2}$ in the production of ethylene oxide. One possibility for lowering the losses due to nonselectivity is the development of more selective catalysts. Past examples of selectivity improvements using better catalysts are numerous. For instance, the selectivity in ethylene oxide production increased from around $70 \%$ in the 1960 s to more than $80 \%$ nowadays [14]) and the selectivity of catalysts used in acrylonitrile production has also steadily improved over time [31]. These two processes, however, are still at the top of our list of processes with large losses due to non-selectivity, thus leaving room for further improvements.

A chemical process can, in a simplified way, be seen as the combination of a reaction section and a separation/ purification section. Separation/purification normally requires energy, whereas the reaction section is either an energy consumer (endothermic conversions) or an energy producer (exothermic conversions). In this paper, we did not separately identify losses in the reaction and separation/purification sections. With respect to the chemical conversions, both Leites et al. [6] and Korevaar [7] argued that it is desirable from an exergy point of view to perform exothermic reaction at high temperatures and to supply heat to endothermic reactions at the lowest possible temperatures (if possible, via coupling with an exothermic reaction). This contradicts, however, the desire for a high degree of conversion, which is favoured by low temperatures for exothermic reactions and high temperatures for endothermic reactions ${ }^{9}$. Process concepts that can help partly overcome this contradiction are heat exchange and membrane reactors. If a heat-exchange reactor is applied for exothermic conversions, a gradual decrease in temperature can be used so that part of the reaction is conducted at a high temperature (to allow withdrawal of heat at a high-temperature level) and part at a low temperature (to reach a reasonable degree of conversion). Given the importance of the heat effect of reaction in the total energy loss of the process (Fig. 8), it is clear that the potential benefit of such reactors for the processes analysed in this study could be substantial. This is confirmed in a study by Hugill [32]. The application of membrane reactors can help to shift the equilibrium in reactors, allowing operation at more favourable reactor conditions. The application of membranes in the production of synthesis gas used for ammonia production can, for example, help to reach the same conversion rates in the endothermic reaction at a much lower temperature [33].

Another, more drastic way to reduce energy losses is to shift to other process routes, using other raw materials. As shown by Lange [14], past changes in choice of raw materials often resulted in a lower heat effect of reaction and lower energy losses. In another paper [16], Lange mentions caprolactam, adipic acid and vinyl

\footnotetext{
${ }^{9}$ The desire for a high temperature is also limited by the availability of material that can withstand high temperature with negligible corrosion. Material improvement is therefore also a direction to reduce energy losses.
} 
chloride as products for which research activities on alternative routes are taking place. Not surprisingly, these processes also appear in the lists of processes with large losses presented in Section 3 of this paper. Another option is to make use of biomass raw materials or bioconversion technologies such as enzymatic conversions and/or fermentation. The potentials for such routes (e.g., for caprolactam and adipic acid present in our lists of processes with large losses) have been studied by a number of researchers $[34,35]$.

According to the first law of thermodynamics, energy cannot be lost. Therefore, the energy loss calculated in this study equals the flow of waste heat to the environment in the form of cooling water, hot off-gases from furnaces, etc. Even without the process improvements considered above, one general focus for energy savings is to find a suitable use for this waste heat. Whether or not waste heat can be used for applications such as heat pumps, heating of buildings, etc, depends, among other things, on the temperature level of the waste heat flow to the environment. Without looking into the processes, it is not possible to analyse the temperature of the waste heat disposal. Other studies $[36,37]$ have shown that at least some of the waste heat becomes available at temperature levels suitable for such useful applications (exceeding $50^{\circ} \mathrm{C}$ ). Examples of waste heat applications in the Rotterdam area are its use for space heating [38] and it being used by other industries via co-siting [39].

\section{Discussion}

\subsection{Uncertainties}

The number of datasets taken into account in our calculations ranged from 1 to 12 per process. For those process routes for which several datasets were available, we used the dataset most likely to represent the average technology used in Western Europe in 2000. In cases, where only one process dataset was available, we use this dataset without adjusting for process improvements that might have taken place over time. Unfortunately, information on highly energy-integrated chemical plants was not available for this study. For this reason, the results for the individual processes may have a significant range of uncertainty. Based on the number of process datasets available and on the types of sources used, we marked the processes for which we estimated the final energy use data shown in Fig. 2 to have an uncertainty of less than 10\% (21 of the 68 processes) with a ' 1 ' in Appendix A. For most of the remaining processes, we estimated the uncertainty to be between $10 \%$ and $30 \%$ and marked them with a ' 2 ' in Appendix A (34 of the 68 processes). Those processes with an even higher uncertainty range (over $30 \%$ ), based on one single source published before 1990 (e.g., Chauvel and Lefebvre [31]) are marked with a ' 3 ' in Appendix A (13 of the 68 processes).
We did not account for geographical differences in energy efficiency between and within the three regions studied. Instead, we based all analyses on process energy data that were considered representative for Western Europe. Some insight in the ranges observed in practice can be obtained by looking at the ranges for processes reported in literature. For example, ranges for fuel use in steam crackers of 15-25 GJ/tonne ethylene for ethane cracking, 25-40 GJ/tonne for naphtha cracking, and 40-50 GJ/tonne for gas oil cracking have been reported for European steam crackers [40]. Since there is no clear indication that European steam crackers are clearly more energy efficient than the worldwide average [41], these ranges can also be regarded as indicative for the worldwide situation for this process. Because such comparative data were not available for most of the processes included, it was difficult to draw robust conclusions about the geographical differences in energy efficiency based on the current set of data. We estimated the uncertainty in the production volumes to be in the order of about $10-20 \%$ and the uncertainties in the shares of the various process routes to be about 5-10\%. We base this range on the capacity data and production volumes from different sources, which are included in the model.

Some of the losses due to non-selectivity are in the form of low-value-fuel-grade by-products. When these fuel by-products are burned, energy might be recovered. If this energy recovery is not deducted from the energy use of the process found in the datasets, the energy use may be double counted as losses due to non-selectivity and again as final energy use. The same is true for carbon losses from reaction. We can conclude from Fig. 5 that such double counting for Western Europe is maximally $138 \mathrm{PJ}_{\mathrm{f}}$ or $9 \mathrm{Mt} \mathrm{CO}_{2} /$ year, approximately $8 \%$ of the total final energy use and $\mathrm{CO}_{2}$ emissions. In reality, double-counting is less, because the losses due to nonselectivity in some of the processes (e.g., ethylene oxide production) are the result of over-oxidation of the feedstock, which leads to direct $\mathrm{CO}_{2}$ emissions and to the formation of heat.

The main focus of this study was on the energy use within the processes rather than on the energy-conversion sector. We therefore calculated the $\mathrm{CO}_{2}$ emissions from steam and electricity generation using the rather simple method described in Section 2.3. In actual practice in the chemical industry, a fraction of the heat and power used is produced in combined heat and power (CHP) plants rather than in the separate systems we assumed. In the year 2000, for example, $215 \mathrm{PJ}_{\mathrm{e}}$ of electricity and $350 \mathrm{PJ}_{\mathrm{f}}$ of heat were produced from $781 \mathrm{PJ}_{\mathrm{p}}$ of fuels in CHP units in the European Union's chemical industry, i.e., with an overall efficiency of $72 \%$ [42]. This is $34 \%$ of the final electricity and $26 \%$ of the final fuel use reported in international energy statistics [18]. A total of $37 \mathrm{PJ}$ electricity and $78 \mathrm{PJ}$ heat was produced in CHP plants in the Dutch chemical industry in 2000, with an overall efficiency of $80 \%$ [43]. 
Table 2

comparison of final energy use and final energy loss in the Netherlands between our model and the Dutch energy statistics for the petrochemical industry

\begin{tabular}{|c|c|c|c|c|}
\hline & Model $^{\mathrm{a}}$ & $\begin{array}{l}\text { Energy } \\
\text { statistics }\end{array}$ & Coverage & $\begin{array}{l}\text { Final energy } \\
\text { loss (Fig. } 8 \text { ) }\end{array}$ \\
\hline & $\mathrm{PJ}_{\mathrm{f}}$ & $\mathrm{PJ}_{\mathrm{f}}$ & $\%$ & $\mathrm{PJ}_{\mathrm{f}}$ \\
\hline Electricity & 18 & 30 & 60 & 18 \\
\hline Fuels & 155 & 117 & 95 & 155 \\
\hline Heat & 45 & 94 & & 45 \\
\hline Feedstock & 328 & 352 & 93 & - \\
\hline $\begin{array}{l}\text { Heat effect } \\
\text { of reaction }\end{array}$ & - & - & - & 32 \\
\hline Total & 546 & 593 & 92 & 251 \\
\hline
\end{tabular}

\footnotetext{
${ }^{\text {a }}$ Feedstock use is raw material input into olefin, ammonia and methanol production minus the fuel use in these processes.

${ }^{\mathrm{b}}$ Based on data from Statistics Netherlands [48]. Electricity use of the organic and other basic chemical industry plus the final non-energy use of electricity in the inorganic basic chemical industry (chlorine production). Fuel use of the organic and other basic chemical industry plus the final energy use of natural gas in the fertiliser industry (ammonia production). Feedstock use (final non-energy use) of the organic and other basic chemical industry plus the final non-energy use of the fertiliser industry (ammonia production).
}

This equals $86 \%$ of electricity use and $43 \%$ of fuel use in 2000 [18]. Total primary energy savings in these CHP plants are $15 \%$ for the European Union and 19\% for the Netherlands compared with our reference of separate production. For fuel and steam use, we used $\mathrm{CO}_{2}$ emissions factors derived from the fuel mix applied in the chemical industry in Western Europe. For electricity, we used an average emission factor and the efficiency of fossil generation of electricity in a few European countries. These emission factors do not take into account processspecific and regional differences or the implementation of combined heat and power. Our simplified approach is justified given the scope of the study. It is, however, important to keep in mind the assumptions made when using data from Appendix A or from the figures shown.

\subsection{Comparison with other sources}

For the Netherlands, we compared the results of the total of processes covered in this study with the energy use of the petrochemical industry (and ammonia and chlorine production), as it can be found in national energy statistics (Table 2). We divided the final energy use into electricity, fuel, and heat use to allow a better comparison. The comparison was complicated, however, by the unclear definition of feedstock use in energy statistics ${ }^{10}$. In the

\footnotetext{
${ }^{10}$ These issues are currently being studied in a research project financed by the European Commission [44].
}

steam reforming and steam cracking processes, the raw material (e.g., natural gas or naphtha) is used partly as feedstock and partly as fuel. The use as fuel can take either directly (e.g., natural gas in ammonia production) or via the intermediate production of fuel gas (steam cracking). In the Netherlands, a net definition of feedstock use is applied in which parts of the raw material that are used as fuel are excluded from the feedstock use ${ }^{11}$. The same system boundaries were applied in Table 2. The results from our model for the use of fuels and heat fit reasonably well with the published Dutch statistics, given the uncertainties in both our model results and the energy statistics. The coverage for electricity use is much lower $(60 \%)$. This can be partly explained by some major electricity consuming processes (e.g., industrial gases) that were not included in our model, but were included in the energy use of the 'other basic chemical industry' in the Dutch energy statistics. Furthermore, our model did not account for the electricity use of on-site facilities such as lighting, and space heating.

Our model could only be compared with energy use data for the chemical industry as a whole for Western Europe and the world, since energy statistics comparable to our system boundaries were unavailable (Table 3). For the Western European and worldwide figures, we assumed a gross definition of feedstock use for olefin production (allocating the total input into the crackers to non-energy use, corrected for reported backflows to refineries) and a net definition of feedstock use for methanol and ammonia production (allocating only the calorific value of the products to feedstock use). Based on a detailed comparison on the level of individual fuels, this choice of definition proved to yield the most reasonable results ${ }^{12}$. We can conclude that the processes included cover approximately $30 \%$ of the electricity use and $70 \%$ of the combined fuel and feedstock use in the chemical sector. This energy coverage is reasonably in line with other available sources:

- According to the US Department of Energy [10], more than $50 \%$ of electricity used in the US is consumed by subsectors of the chemical industry (industrial gases, industrial inorganic chemicals excluding chlorine phosphatic fertilisers) that were not covered in this analysis.

- According to the same source, $47 \%$ of total energy use in the US chemical industry is consumed in the drugs $(6 \%)$, soaps/cleaners $(3 \%)$, agricultural $(9 \%)$, inorganics $(25 \%)$ and other subsectors $(4 \%)$ that were to a large extent not covered by our analysis.

- The heat reported in the international energy statistics only represents heat bought from third parties. The fuel

\footnotetext{
${ }^{11}$ The non-energy use accounting is quite complex in the Netherlands. We refer to Neelis et al. [45] for details.

${ }^{12}$ If a net definition was applied for steam cracking and the fuel use in the crackers was excluded, one would expect a major final use of chemical rest gas in the chemical industry. This is indeed the case for the Netherlands (where a net definition is applied), but not for many other countries.
} 
Table 3

Comparison of final energy use and final energy loss in Western Europe and the world between our model and international energy statistics for the chemical industry.

\begin{tabular}{|c|c|c|c|c|}
\hline & Model $^{\mathrm{a}}$ & $\begin{array}{l}\text { Energy } \\
\text { statistics }^{b}\end{array}$ & Coverage & $\begin{array}{l}\text { Final energy } \\
\text { loss (Fig. 8) }\end{array}$ \\
\hline & $\mathrm{PJ}_{\mathrm{f}}$ & $\mathrm{PJ}_{\mathrm{f}}$ & $\%$ & $\mathrm{PJ}_{\mathrm{f}}$ \\
\hline \multicolumn{5}{|l|}{ Western } \\
\hline \multicolumn{5}{|l|}{ Europe } \\
\hline Electricity & 197 & 674 & 29 & 197 \\
\hline Fuels & 306 & 1337 & 42 & 987 \\
\hline Heat & 285 & 58 & & 285 \\
\hline Feedstock & 2246 & 2752 & 82 & 一 \\
\hline $\begin{array}{l}\text { Heat effect } \\
\text { of reaction }\end{array}$ & - & - & - & 151 \\
\hline Total & 3034 & 4821 & 63 & 1620 \\
\hline \multicolumn{5}{|l|}{ World } \\
\hline Electricity & 844 & 3131 & 26 & 844 \\
\hline Fuels & 3040 & 9194 & 43 & 5700 \\
\hline Heat & 1503 & 1155 & & 1503 \\
\hline Feedstock & 12,379 & 14,414 & 86 & - \\
\hline $\begin{array}{l}\text { Heat effect } \\
\text { of reaction }\end{array}$ & - & - & - & 658 \\
\hline Total & 17,665 & 27,894 & 63 & 8709 \\
\hline
\end{tabular}

${ }^{\mathrm{a}}$ Except for $40 \%$ of the fuel use in ethane crackers (which require nonfeedstock-derived fuels; 9 PJ in WE, 168 PJ worldwide), fuel use excludes the fuel use in olefin production. This fuel use is included in feedstock use, see the text for further explanation. The feedstock use is the raw material input into ammonia and methanol production minus the fuel use in these processes and the raw material input into olefin production minus backflows from olefin production to the refineries as reported in the energy statistics (631 PJ in Western Europe; 1108 PJ worldwide).

${ }^{\mathrm{b}}$ Energy statistics from IEA [2,18].

reported as final consumption includes fuel used for direct fuel applications (e.g., in furnaces) as well as fuel used for steam generation, either in stand-alone steam boilers or in cogeneration plants, but excludes the amount of fuel used for the generation of electricity in cogeneration units, which should be reported in the energy-conversion sector ${ }^{13}$. As a result, the fuel consumption figures in the energy statistics include losses in steam generation, which are not included in final energy use figures according to our model (Fig. 8).

\footnotetext{
${ }^{13}$ This practice raises the question of how the fuel input in autoproducer CHP plants is allocated to the electricity and heat produced. In the electricity and heat survey, the countries are asked to use national methodologies. In cases where an adequate national method is lacking, the IEA recommends allocation of the input between electricity and heat in proportion to the energy content of the heat and electricity produced [46]. This latter method leads to steam-generation efficiencies equal to the overall efficiency of the cogeneration units, which in the chemical industry in the European Union averages $72 \%$ (Section 5.1). When this efficiency is applied to the steam generated in CHP plants (Section 5.1) we can conclude that the final fuel use according to the energy statistics includes $136 \mathrm{PJ}$ of energy lost in steam generation. Deducting this amount from the reported final fuel use leads to a coverage of $47 \%$ in Western Europe.
}

\section{Conclusions}

We prepared energy and carbon balances for 68 processes in the petrochemical industry. We analysed the sum of all energy inputs (both process energy use and the energy content of the raw materials) that do not end up in the useful products of the process, but are lost to the environment. The total energy loss identified can be regarded as a good approximation of the theoretical energy-saving potential of the processes analysed. For the total of the processes studied, we estimated the energy loss in Western Europe in the year 2000 to be $1936 \mathrm{PJ}_{\mathrm{p}}$, resulting in a total of $127 \mathrm{Mt} \mathrm{CO}_{2}$. We distinguished between excess final energy use, losses due to nonselectivity and energy-conversion losses, which contributed $77 \%, 7 \%$ and $16 \%$, respectively, to the total energy loss. Similar divisions were found for the Netherlands and the world, where total losses were quantified at 282 and $10092 \mathrm{PJ}_{\mathrm{p}}$, respectively. We showed that both the heat effect of reaction and the process energy use contribute significantly to the overall energy loss of the individual processes and recommend that studies on energy-efficiency improvement potentials in the chemical industry address the heat effect of reaction (which is not directly visible in energy statistics) more explicitly. We identified several processes with large energy losses and advocate that they be further analysed to identify technical and economic saving potentials, taking into account further thermodynamic, economic and practical limitations to energy-saving options. Such analyses will require more in-depth studies at the level of unit operations, taking into account aspects related to the second law of thermodynamics. We showed that the potential energy savings from the implementation of BAT processes might in the order of $10-50 \%$ of the current final energy use. Based on the types of losses distinguished, we gave some general directions of energy savings, such the use of more selective catalysts to reduce losses due to non-selectivity, the use of novel process concepts such as membrane or heat-exchange reactors, the use of totally new process routes based on biomass, and a better use of waste heat available form the various processes.

\section{Acknowledgements}

We would like to thank Evert Nieuwlaar (Utrecht University, Copernicus Institute, Unit Science, Technology and Society) and Jean-Paul Lange (Shell) for their review of previous drafts of this paper.

\section{Appendix A}

See for Table A1. 


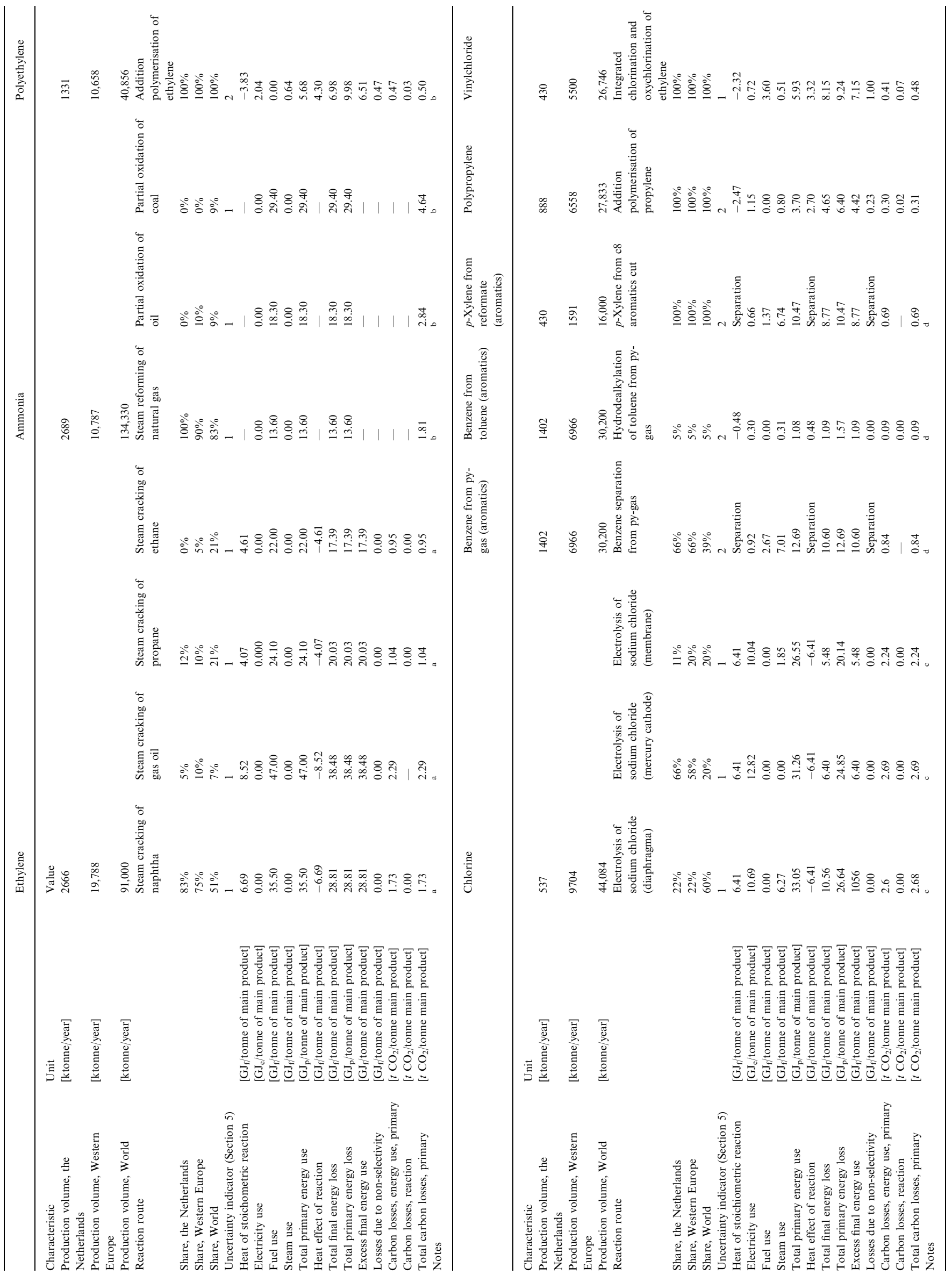




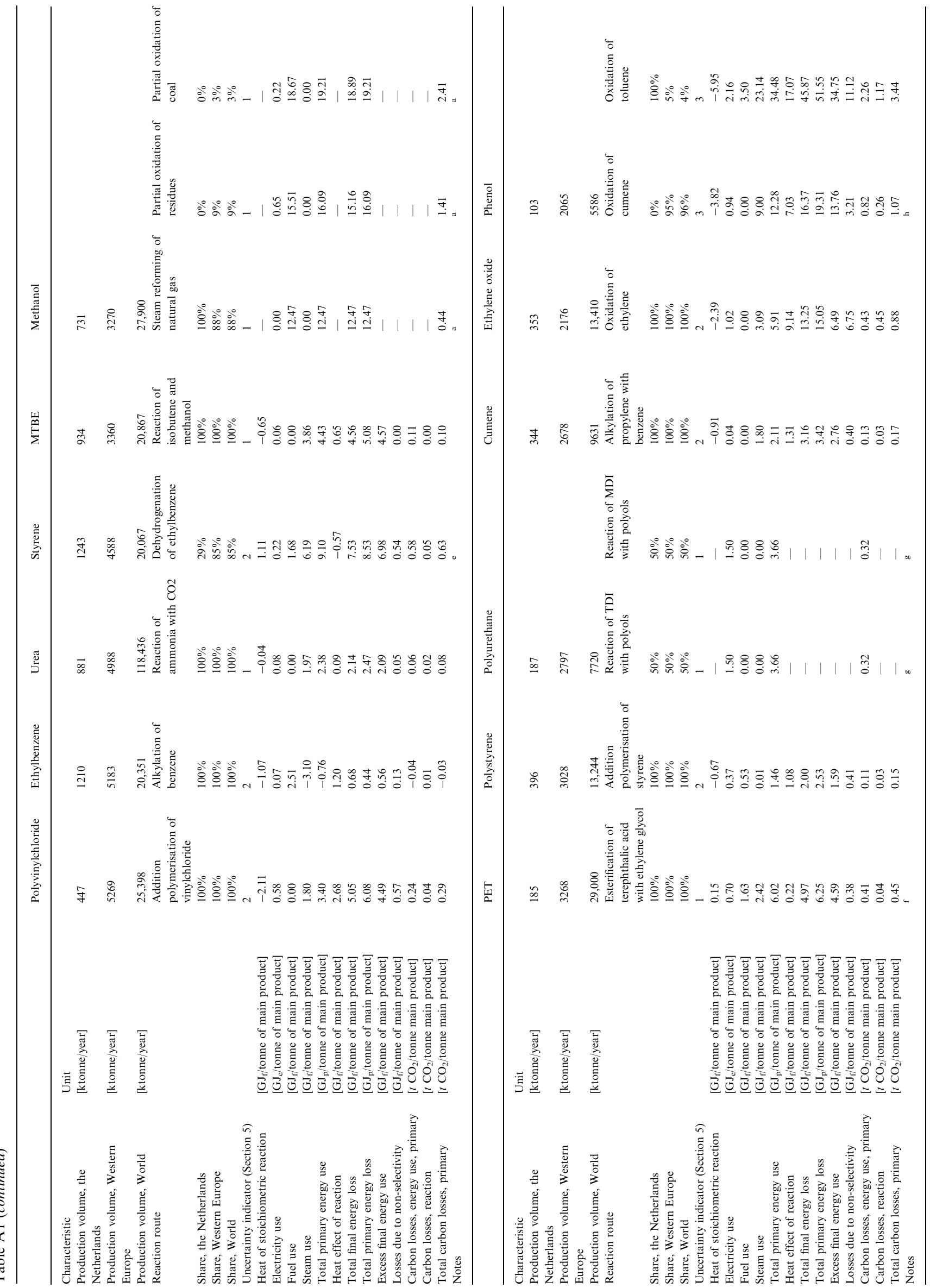




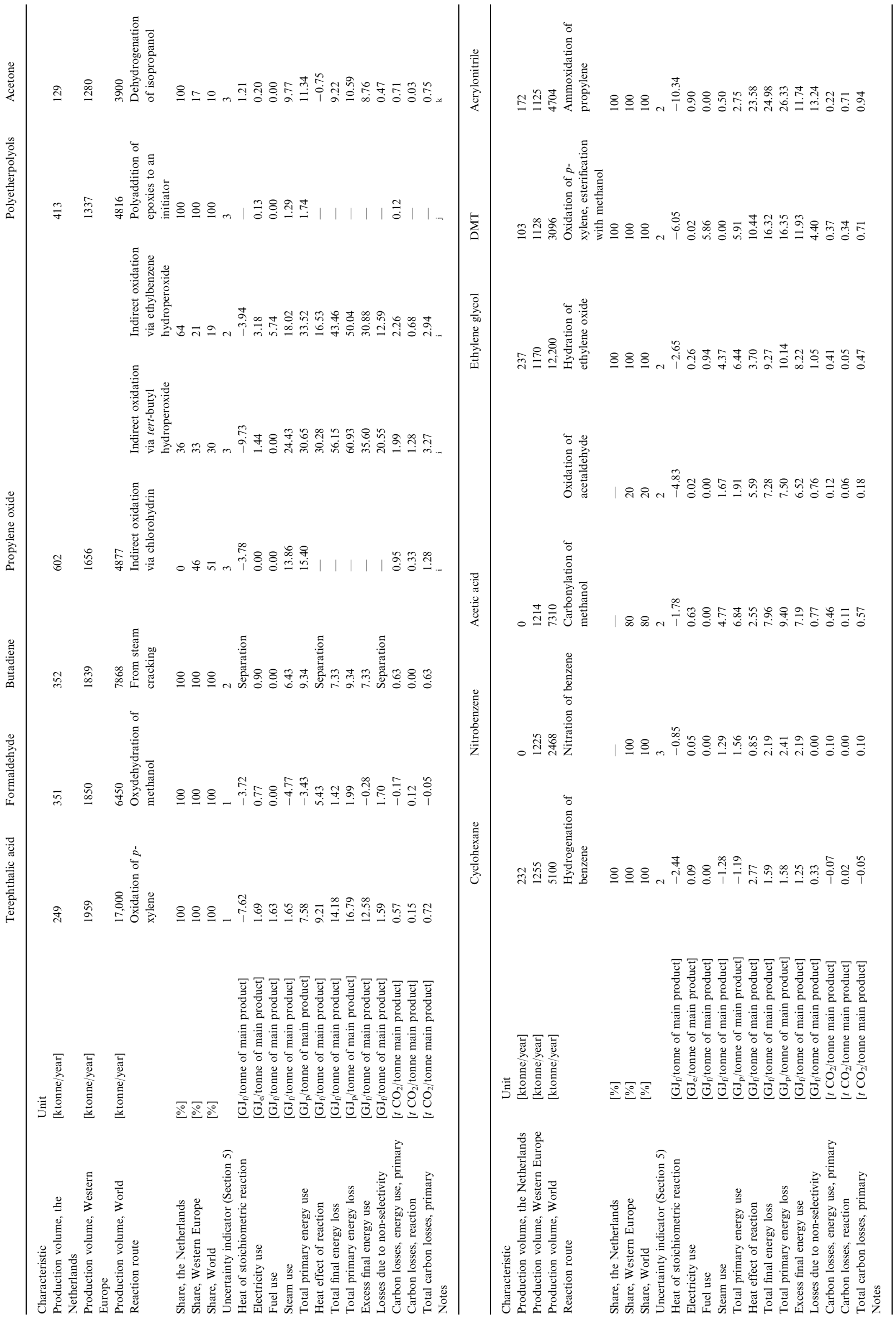




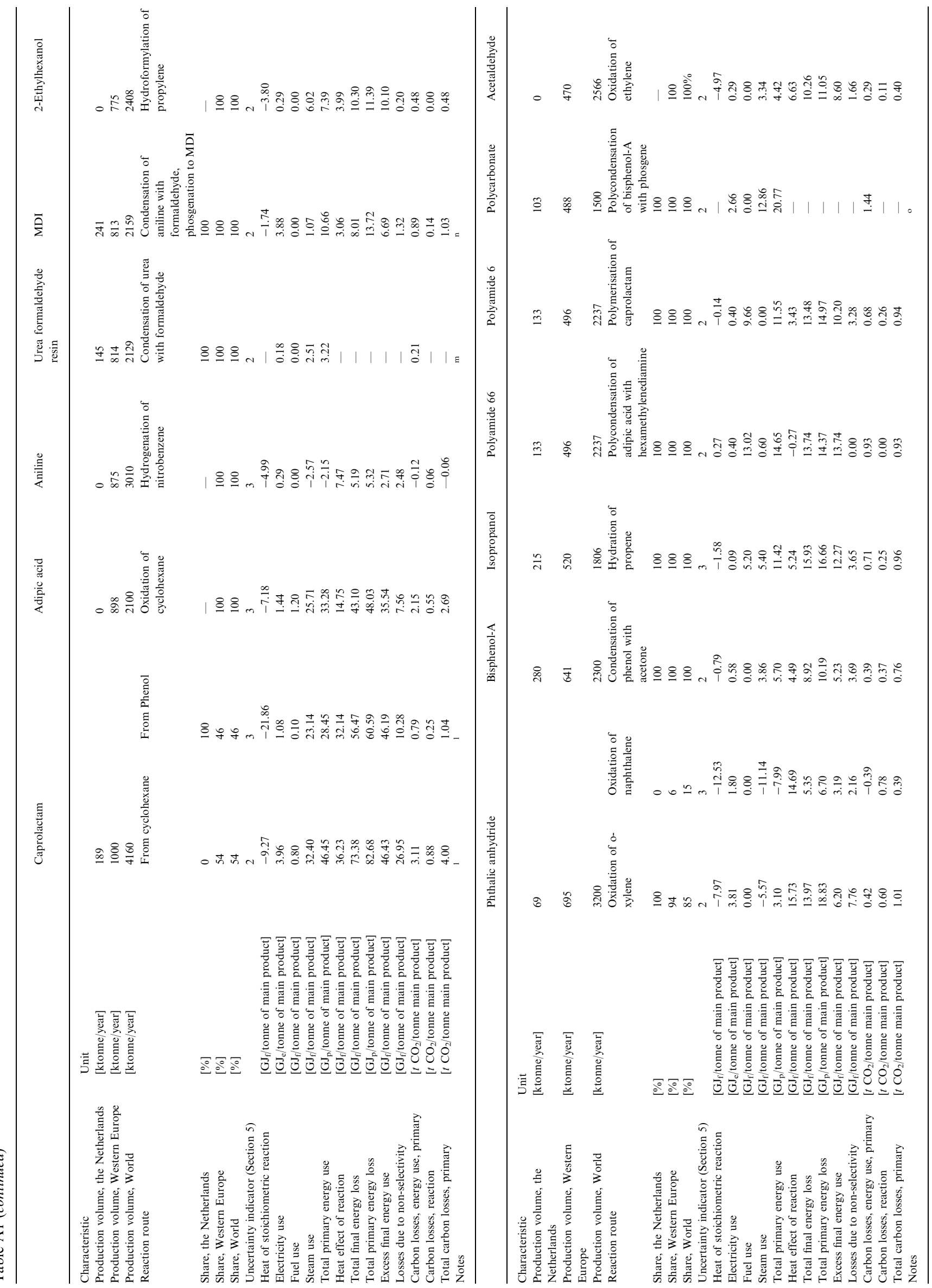




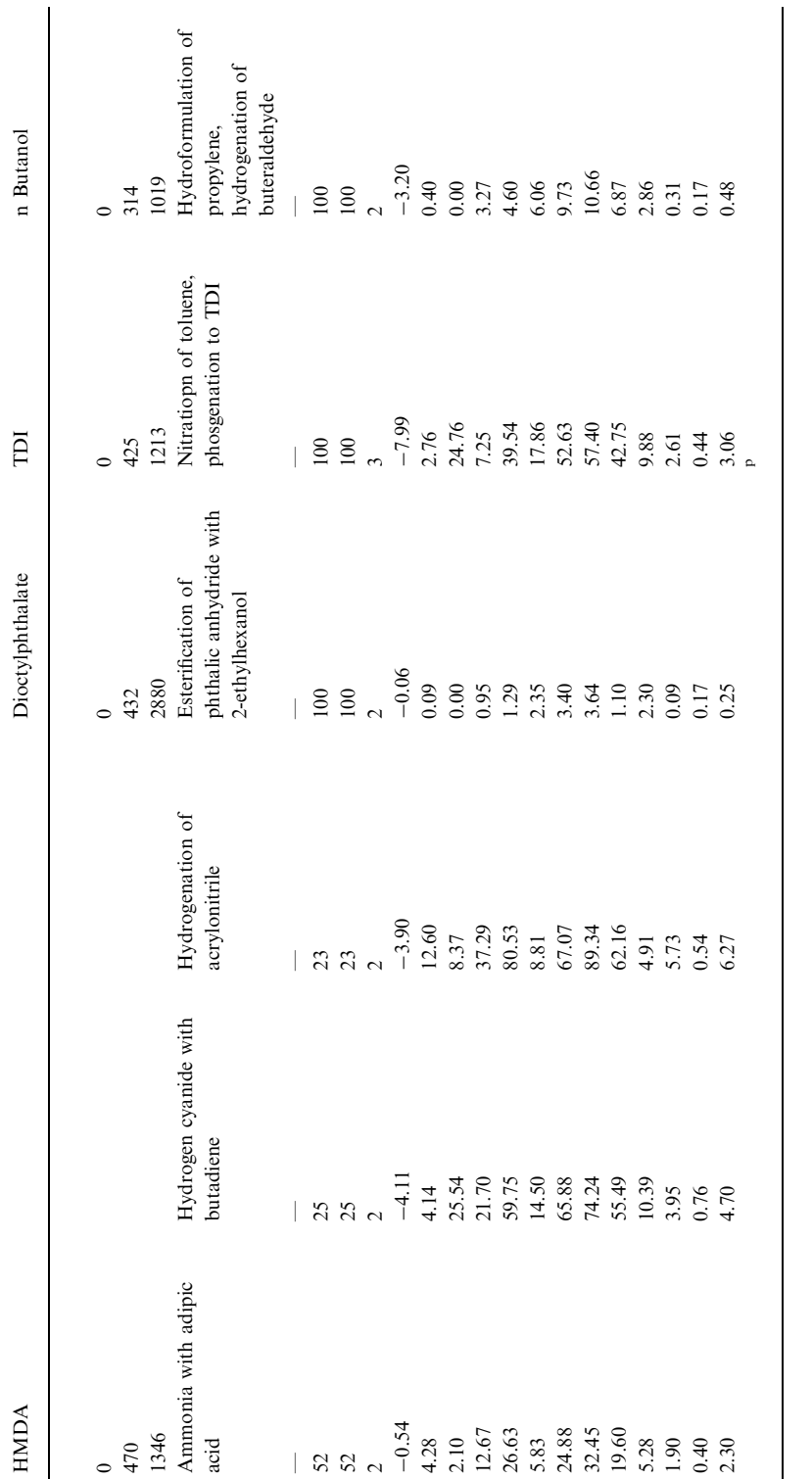

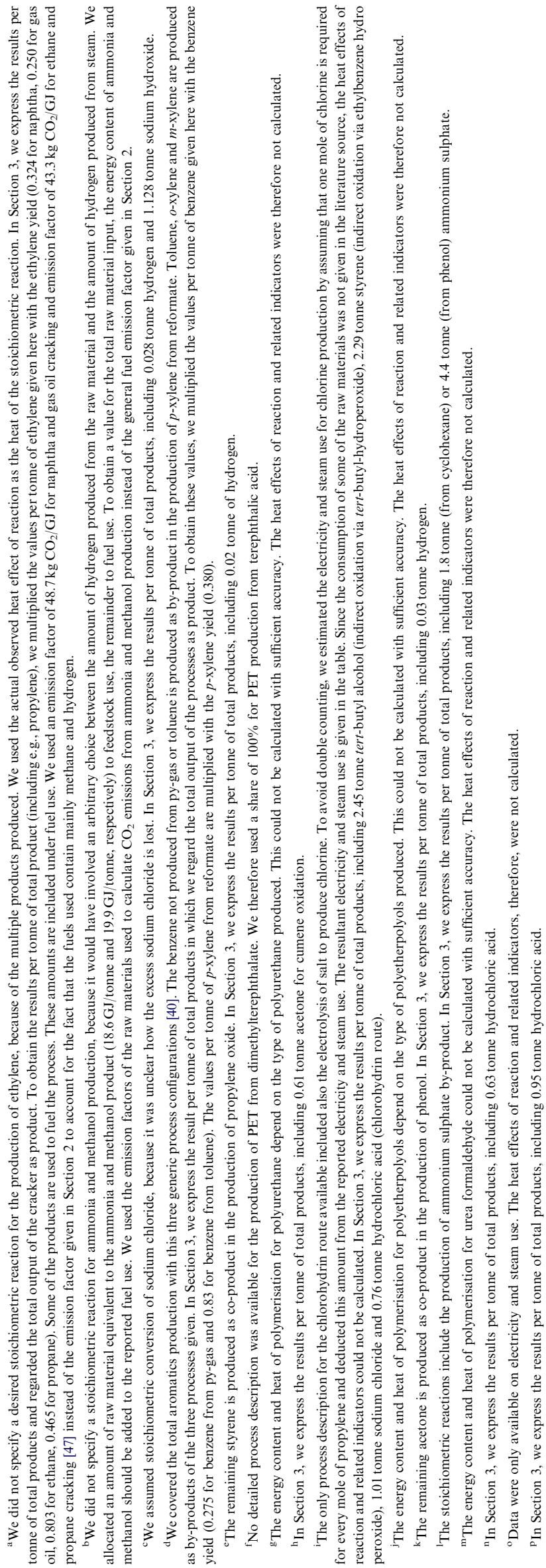




\section{References}

[1] Neelis M, Patel M, Blok K, Bach, PW. Analysis of energy use and carbon losses in the chemical industry. Appl. Energy, accepted for publication.

[2] International Energy Agency (IEA). Extended energy balances of non-OECD countries, 2002 edition, Paris: IEA; 2002.

[3] Hinderink AP, Kerkhof FPJM, Lie ABK, de Swaan Arons J, van der Kooi HJ. Exergy analysis with a flowsheeting simulation-II. Application; synthesis Gas production from natural gas. Chem Eng Sci 1996;51(20):4701-15.

[4] Radgen P. Pinch and exergy analysis of a fertilizer complex, part 2. Nitrogen 1997;225:27-39.

[5] Radgen P. Pinch and exergy analysis of a fertilizer complex, part 1. Nitrogen 1996;224:30-8.

[6] Leites IL, Sama DA, Lior N. The theory and practice of energy saving in the chemical industry: some methods for reducing thermodynamic irreversibility in chemical technology processes. Energy 2003;28:55-97.

[7] Korevaar G. Sustainable chemical processes and products - new design methodology and design tools. PhD thesis. Delft, University of Technology Delft, 2004.

[8] Association of Plastics Manufacturing in Europe (APME). Eco-profiles of the european plastics industry. Various reports on different types of plastics, prepared by Dr. I. Boustead. APME, Brussels, 1994-2003.

[9] Gielen DJ, Vos D, van Dril AWN. The petrochemical industry and its energy use, prospects for the Dutch energy intensive industry. Report ECN-C - 96-029, Energy Research Centre of the Netherlands $(\mathrm{ECN})$, Petten.

[10] US Department of Energy, Office of Industrial Technologies (DOE/ OIT). Energy and Environmental Profile of the US Chemical Industry. DOE/OIT, Washington.

[11] Worrell E, Phylipsen D, Einstein D, Martin N. Energy use and energy intensity of the US chemical industry. Ernest Orlando Lawrence Berkeley National Laboratory, Energy Analysis Department, Environmental Energy Technologies Division, Berkeley, CA, 2000.

[12] Joosten L. The industrial metabolism of plastics - analysis of material flows, energy consumption and $\mathrm{CO}_{2}$ emissions in the lifecycle of plastics. PhD thesis, Utrecht University, Utrecht, 2001.

[13] Patel M. Cumulative energy demand (CED) and cumulative $\mathrm{CO}_{2}$ emissions for products of the organic chemical industry. Energy 2003;28:721-40.

[14] Lange JP. Fuels and chemicals manufacturing-guidelines for understanding and minimizing the production costs. CATTECH 2001;5(2):82-95.

[15] Tonkovich ALY, Gerber MA. The top 50 commodity chemicals: impact of catalytic process limitations on energy, environment, and economics. Pacific Northwest Laboratory, Richland, 1995.

[16] Lange JP. Sustainable development: efficiency and recycling in chemicals manufacturing. Green Chem 2002;4(6):546-50.

[17] Szargut J, Morris DR, Steward FR. Exergy analysis of thermal, chemical and metallurgical processes. Berlin: Springer Verlag; 1988.

[18] International Energy Agency. Extended energy balances of OECD countries, Paris: IEA; 2002.

[19] Aspen Technology. Aspen Properties, part of Aspen Engineering Suite 11.1. Cambridge, Massachusetts, 2001.

[20] Brandrup J, Immergut E. Polymer handbook, third ed. New York: Wiley; 1989.

[21] Intergovernmental Panel on Climate Change (IPCC), International Energy Agency (IEA), Organisation for Economic Cooperation and Development (OECD) and United Nations Environment Programme (UNEP). Revised 1996 IPCC guidelines for national greenhouse gas inventories programme, volume 1-3. IPCC WGI Technical Support Unit, Bracknell, 1997
[22] Patel M. Personal communication with industry. 1998.

[23] Statistics Netherlands. Explanation of survey Z029, oil feedstock and oil products (Toelichting op Z029, aardoliegrondstoffen en aardolieproducten). Statistics Netherlands, Voorburg [in Dutch].

[24] Graus W, Voogt M. Updated comparison of power efficiency on grid level. Ecofys, Utrecht, 2005

[25] Chemical Market Reporter. Various issues of this journal, 1994-2005.

[26] European Chemical News. Various issues of this journal, 1994-2005.

[27] Chemical Week. Various issues of this journal, 1994-2005.

[28] Weissermel K, Arpe HJ. Industrial organic chemistry fourth ed. Wiley-VCH, Weinheim; 2003 [completely revised].

[29] Vereniging van de Nederlandse Chemische Industrie (VNCI). Yearly report (Jaarverslag), Leidschendam: VNCI; 2003 [in Dutch].

[30] Neelis ML, Patel MK, Bach PW, Haije WG. Analysis of energy use and carbon losses in the chemical and refinery industries. Report ECN-I-05-008, Energy research Centre of the Netherlands (ECN), Petten, 2005.

[31] Chauvel A, Lefebvre G. Petrochemical processes, technical and economic characteristics; Part 1: synthesis-gas derivatives and major hydrocarbons and Part 2: major Oxygenated, chlorinated and nitrated compounds. Editions Technip, Paris, 1989.

[32] Hugill JA. HEX-reactor applications in the Netherlands - a nonconfidential summary. Report ECN-C-03-015. Energy Research Centre of the Netherlands (ECN), Petten, 2003.

[33] Delft Y, Correia L, Overbeek J, Meyer D, Pex P, Dijkstra J, et al Hydrogen membrane reactor for industrial hydrogen production and power generation, in: Seventh International conference on catalysis in membrane reactors, Cetraro, Italy, 2005.

[34] Crank M, Patel MK, Marscheider-Weidemann F, Schleich J, Hüsing B, Angerer G. Techno-economic feasibility of large-scale production of bio-based polymers in Europe (PRO-BIP). Utrecht: Copernicus Institute, Department of Science, Technology and Society; 2004.

[35] van Tuil R, de Jong E, Scott E, Weusthuis R, Vellema S, de Keizer I, et al. Biomass for the chemical industry. CE, Delft, 2004.

[36] Carp JA, Bach PW. Market potential for thermohydraulic engines using waste heat sources. Report ECN-EEI 7.6409-GR 01/1. Energy Research Centre of the Netherlands (ECN), Petten, 2001.

[37] Spoelstra S, Haije WG, Dijkstra JW. Techno-economic feasibility of high-temperature high-lift chemical heat pumps for upgrading industrial waste heat. Appl Thermal Eng 2002;22:1619-30.

[38] Anonymous. First steps in a new heat distribution network in Rotterdam (Eerste stap in nieuw warmtedistributienet in Rotterdam). Viewed on http://www.energiemanagement.net. September 2004 [in Dutch].

[39] Anonymous. Co-siting. Information provided on http://www.portofrotterdam.com. 2005.

[40] European Commission, Joint Research Centre, Institute for Prospective Technological Studies. Reference document on best available techniques in the large volume organic chemical industry. Seville, 2004.

[41] Phylipsen D, Blok K, Worrell E, de Beer J. Benchmarking the energy efficiency of the Dutch industry: an assessment of the expected effect on energy consumption and $\mathrm{CO}_{2}$ emissions. Energy Policy 2002;30(8): $663-79$.

[42] Loesoenen P. Combined heat and power (CHP) plant statistics in the EU, 2000. Statistics in Focus, Theme 8. Eurostat, Luxemburg, 2003.

[43] Statistics Netherlands. Production of electricity (Productie middelen electriciteit). Statistics Netherlands, 2004. Viewed via statline: http:// www.cbs.nl [in Dutch].

[44] Non-energy use and $\mathrm{CO}_{2}$ emissions. Project funded by the European Commission, 1999-2006. Project website: http://www.chem.uu.nl/ nws/www/nenergy/.

[45] Neelis M, Patel M, Blok K. $\mathrm{CO}_{2}$ emissions and carbon storage resulting from the non-energy use of fossil fuels in the Netherlands, 
NEAT results for 1993-1999. Resources, Conservation Recycling 2005;45:251-74.

[46] International Energy Agency (IEA). Electricity and heat: annual questionnaire, IEA, Paris, 2003.

[47] Neelis $\mathrm{M}$, Patel $\mathrm{M}$, de Feber $\mathrm{M}$. Improvement of $\mathrm{CO}_{2}$ emission estimates from the non-energy use of fossil fuels in the Netherlands.
Report NW \& S-E-2003-10. Copernicus Institute, Department of Science, Technology and Society, Utrecht, 2003.

[48] Statistics Netherlands, Energy balances for the chemical industry (Energie balansen voor de chemische industrie), 2005. Viewed via statline: http://www.cbs.nl [in Dutch]. 